\title{
QNREL
}
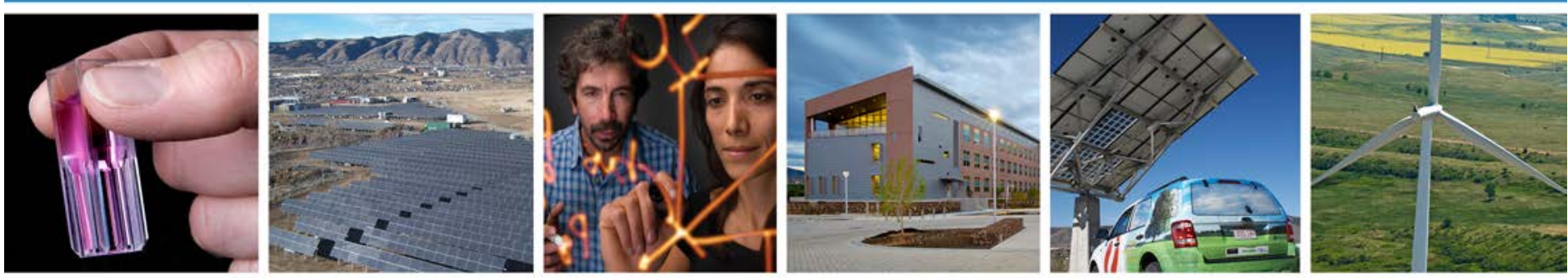

\section{Centralized and Modular Architectures for Photovoltaic Panels with Improved Efficiency}

\section{Preprint}

Bishal Dhakal and Fernando Mancilla-David University of Colorado at Denver

Eduard Muljadi

National Renewable Energy Laboratory

To be presented at the North American Power Symposium Urbana, Illinois

September 9-11, 2012

NREL is a national laboratory of the U.S. Department of Energy, Office of Energy Efficiency \& Renewable Energy, operated by the Alliance for Sustainable Energy, LLC.

Conference Paper

NREL/CP-5500-55894

July 2012

Contract No. DE-AC36-08G028308 


\section{NOTICE}

The submitted manuscript has been offered by an employee of the Alliance for Sustainable Energy, LLC (Alliance), a contractor of the US Government under Contract No. DE-AC36-08GO28308. Accordingly, the US Government and Alliance retain a nonexclusive royalty-free license to publish or reproduce the published form of this contribution, or allow others to do so, for US Government purposes.

This report was prepared as an account of work sponsored by an agency of the United States government. Neither the United States government nor any agency thereof, nor any of their employees, makes any warranty, express or implied, or assumes any legal liability or responsibility for the accuracy, completeness, or usefulness of any information, apparatus, product, or process disclosed, or represents that its use would not infringe privately owned rights. Reference herein to any specific commercial product, process, or service by trade name, trademark, manufacturer, or otherwise does not necessarily constitute or imply its endorsement, recommendation, or favoring by the United States government or any agency thereof. The views and opinions of authors expressed herein do not necessarily state or reflect those of the United States government or any agency thereof.

Available electronically at http://www.osti.gov/bridge

Available for a processing fee to U.S. Department of Energy and its contractors, in paper, from:

U.S. Department of Energy

Office of Scientific and Technical Information

P.O. Box 62

Oak Ridge, TN 37831-0062

phone: 865.576 .8401

fax: 865.576 .5728

email: mailto:reports@adonis.osti.gov

Available for sale to the public, in paper, from:

U.S. Department of Commerce

National Technical Information Service

5285 Port Royal Road

Springfield, VA 22161

phone: 800.553 .6847

fax: 703.605.6900

email: orders@ntis.fedworld.gov

online ordering: http://www.ntis.gov/help/ordermethods.aspx

Cover Photos: (left to right) PIX 16416, PIX 17423, PIX 16560, PIX 17613, PIX 17436, PIX 17721

Printed on paper containing at least $50 \%$ wastepaper, including $10 \%$ post consumer waste. 


\title{
Centralized and Modular Architectures for Photovoltaic Panels with Improved Efficiency
}

\author{
Bishal Dhakal and Fernando Mancilla-David \\ Department of Electrical Engineering \\ University of Colorado Denver \\ Denver, Colorado 80217 USA \\ Email: Bishal.Dhakal[Fernando.Mancilla-David]@ucdenver.edu
}

\author{
Eduard Muljadi \\ National Renewable Energy Laboratory \\ Golden, Colorado 80401 USA \\ Email: Eduard.Muljadi@nrel.gov
}

\begin{abstract}
The most common type of photovoltaic (PV) installation in residential applications is the centralized architecture. This realization aggregates a number of solar panels into a single power converter for power processing. The performance of a centralized architecture is adversely affected when it is subject to partial shading effects due to clouds or surrounding obstacles, such as trees. An alternative modular approach can be implemented using several power converters with partial throughput power processing capability. This paper presents a detailed study of these two architectures for the same throughput power level. The study compares the overall efficiency of these two different topologies, using a set of rapidly-changing real solar irradiance data collected by the Solar Radiation Research Laboratory (SRRL) at the National Renewable Energy Laboratory (NREL). This provides an opportunity to study both schemes using real measured data. The output power of both the topology is compared against the panel ideal power. Hence, the efficiency is overall in nature. The electrical efficiency is another form of computation which uses the panel maximum available power as input instead of panel ideal power. The paper uses overall efficiency for all analysis. The buck converter along with the Perturb \& Observe maximum power point tracking algorithm were selected to perform the study. A detail power loss analysis is also presented in the paper. Analytical results are validated through detailed computer simulations using the Matlab/Simulink mathematical software package.
\end{abstract}

\section{INTRODUCTION}

A centralized PV park scheme is composed of a number of series-connected modules connected in parallel to match the load requirements. This scheme is very popular for residential applications. Shading [1], usually in the form of clouds or trees, causes the system overall efficiency to drop significantly. The modular architecture, which is commonly known as "converter per panel," has some distinctive advantages over the centralized type. Among the various converter topologies [1], it has been found that the $\mathrm{dc} / \mathrm{dc}$ buck realization can always deliver any combination of panel power. It has also been demonstrated that modular maximum power point tracking (MPPT) algorithms have resulted in a net overall efficiency gain of up to $25 \%$ [2]. Thus, the "converter per panel" technique is the most convincing way of dealing with time varying environmental conditions. This is particularly true for installations in urban environments. The use of a series type $\mathrm{dc} / \mathrm{dc}$ converter on each panel allows the PV voltage to be individually optimized for peak power tracking. However, the actual power savings of an experimental modular can be a challenging task to calculate under realistic conditions. The results are highly sensitive to the accuracy of the proposed $\mathrm{dc} / \mathrm{dc}$ converter topology and the solar irradiation pattern. The losses in the dc/dc converter needs to be minimized and extra design consideration will be required to improve the overall efficiency. This paper presents a comparative study between centralized and modular architectures. For an actual implementation, adequate communication architecture would be needed for proper synchronization of the various modules. However, this is out of the scope of this paper. The rest of the paper is organized as follows. Section II highlights the main features of PV modules. In Section III details are provided for the formation of PV arrays given the experimental data available. The maximum power point tracking used in this paper is described in Section IV, followed by details on the case study in Section V. Section VI and Section VII discuss the comparative study, and the conclusions of Section VIII close the paper.

\section{PV MODULE STUDY}

Solar panels are composed of a number of cells and each solar cell can be treated as a semiconductor of a $\mathrm{P}-\mathrm{N}$ junction, which converts solar energy into electrical energy. The basic PV module [2]-[6] is shown in Fig. 1. This module is commonly known as a "single diode model."

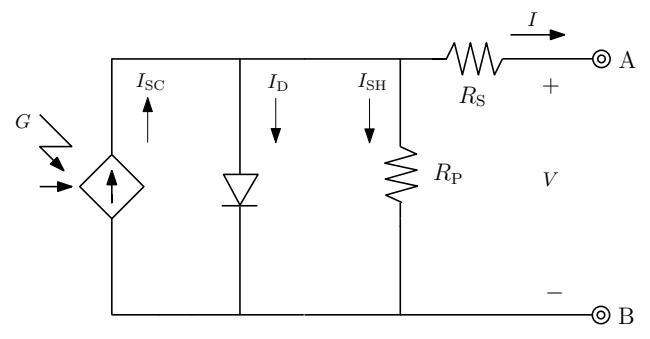

Fig. 1. A typical single-diode model of a solar cell.

The overall Voltage-Current (V-I) characteristics of the PV module can be described by the following equation:

$$
I=I_{\mathrm{SC}}-I_{0}\left[\exp \left(\frac{q\left(V+I R_{\mathrm{S}}\right)}{n K T}\right)-1\right]-\left(\frac{V+I R_{\mathrm{S}}}{R_{\mathrm{P}}}\right),
$$


where $I_{\mathrm{SC}}$ is short circuit current proportional to the solar irradiance $(\mathrm{G}), I_{0}$ is the reverse saturation current, $q$ is the electronic charge, $k$ is the Boltzmann constant, $n$ is the ideality factor, $T$ is the cell temperature, $R_{\mathrm{S}}$ is the cell series resistance, and $R_{\mathrm{P}}$ is the cell parallel resistance. Equation (1) can be solved by an iterative process. Several papers [6], [7] propose different methods of solving (1).

The initial value [8] of cell parallel resistance $R_{\mathrm{P}}$ can be chosen as,

$$
R_{\mathrm{P}}=\frac{150 V_{\mathrm{OC}}}{I_{\mathrm{SC}}}
$$

where

$$
V_{\mathrm{OC}}=V_{\mathrm{OC} @ 25^{\circ} \mathrm{C}}+\beta(T-25)
$$

is the panel open circuit voltage. In (3), $\beta$ is the open circuit voltage temperature coefficient. A detailed simulation was developed using Matlab/Simulink to model single-diode solar cell and also used to create V-I and power voltage $(\mathrm{P}-\mathrm{V})$ characteristics. Figs. 2 and 3 illustrate the V-I and $\mathrm{P}-\mathrm{V}$ characteristics under five different levels of irradiance. These characteristics closely match with manufacturer provided curves. The temperature effects are not shown in this study.

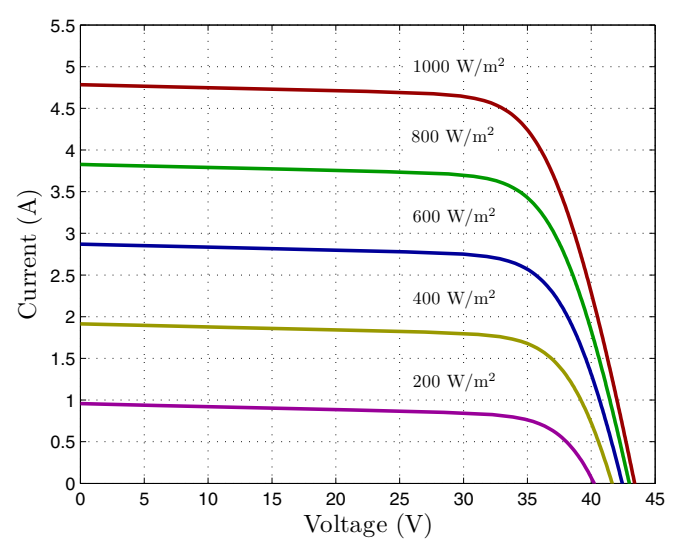

Fig. 2. Simulated V-I curves of SQ150-PC panel at different irradiance at $25^{\circ} \mathrm{C}$.

As it can be seen from these figures, there is only one voltage and current at the point of maximum power. In this study, the SQ150-PC solar module manufactured by Shell was selected as the PV power source. The specification of the SQ150-PC [9] is shown in Table I. The panel has 72 cells connected in series.

\section{CREATION OF SOLAR ARRAY}

In real scenarios, PV panels are usually connected in series, parallel, or a combination of series and parallel to achieve the desired power level. The U.S. Department of Energy's National Renewable Energy Laboratory (NREL) has produced and made available a rich data set showing the second-bysecond effect that clouds play in irradiation over a solar power

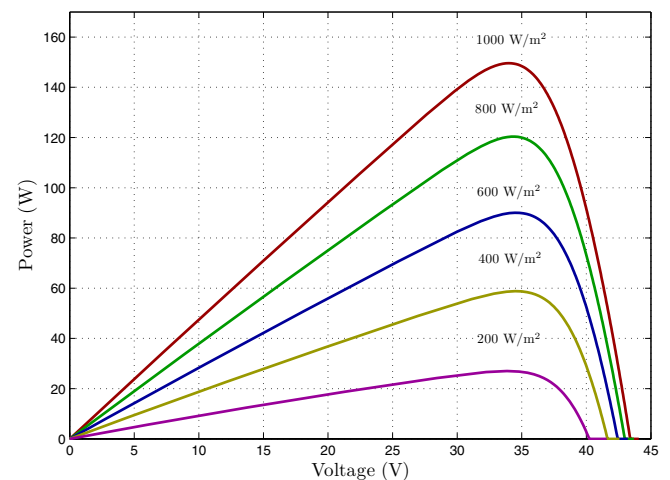

Fig. 3. Simulated P-V curves of SQ150-PC panel at different irradiance at $25^{\circ} \mathrm{C}$

TABLE I

CHARACTERISTICS OF SQ150-PC AT STANDARD CONDITIONS: IRRADIANCE LEVEL $\mathrm{G}=1000 \mathrm{~W} / \mathrm{m}^{2}$, SPECTRUM AM 1.5 AND CELL Temperature $25 C^{\circ}$

\begin{tabular}{cc}
\hline \hline Parameter & Value \\
\hline Rated Power & $150 \mathrm{~W}$ \\
Peak Power & $150 \mathrm{~W}$ \\
Peak Power Voltage & $34 \mathrm{~V}$ \\
Peak Power Current & $4.4 \mathrm{~A}$ \\
Open Circuit Voltage & $43.4 \mathrm{~V}$ \\
Short Circuit Current & $4.8 \mathrm{~A}$ \\
\hline \hline
\end{tabular}

installation in 17 different stations over the course of a year near Hawaii's Honolulu International Airport on the island of Oahu. The data set can be of great help in understanding the cloud effect, as stated before, on mostly large-scale PV installations. All 17 stations make a measurement once every second exactly the same time for 700 seconds.

This allows the array to "see" clouds moving through and simulates how a PV system might behave. Each station has 30 grids and each grid can be represented by a $25 \mathrm{~m}$ by $25 \mathrm{~m}$ area. For this paper, only the first six grids of station 1 were used for simulation. Fig. 4 shows the irradiation patterns for the first six grids of Station 1 over 700 seconds.

To create a grid from a SQ150-PC panel, 31 panels were connected in series to make a string. Then 15 such strings were connected in parallel to create one $25 \mathrm{~m}$ by $25 \mathrm{~m}$ grid. Each SQ150-PC has 72 cells connected in series. Each cell is $125 \mathrm{~mm}$ by $125 \mathrm{~mm}$. Each grid is capable of producing $69.75 \mathrm{~kW}$ at standard conditions. The peak power voltage of each array is $1054 \mathrm{~V}$ and peak power current of 66A. The total number of panels used in one grid is 465 (i.e., $31 \times 15$ ). Fig. 5 shows a creation of one grid using method described above.

\section{DC/DC CONVERTER AND MPPT}

A dc/dc converter converts one level of dc voltage into another. Buck, boost, and buck-boost [10] are three basic types of converters which can be used in PV application. The buck converter steps down the input voltage so that output voltage is always less than the input voltage, whereas the boost 


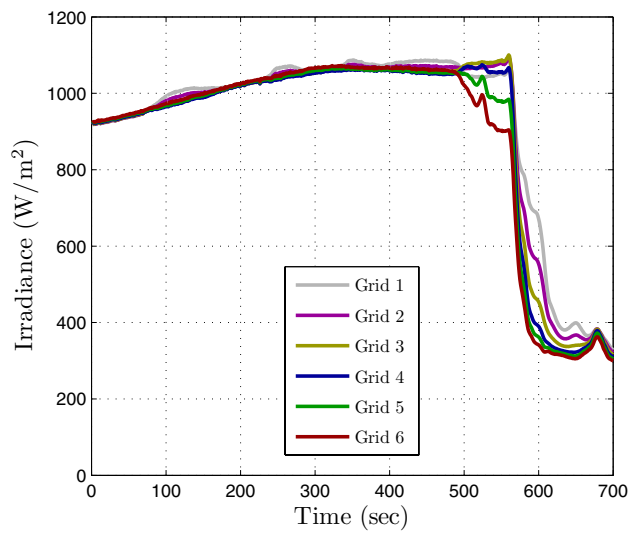

Fig. 4. Irradiance pattern of the six grids of station 1 over 700 seconds.

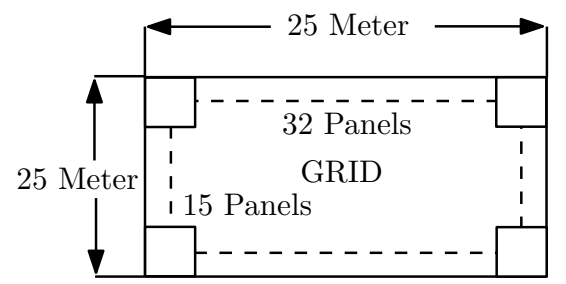

Fig. 5. Creation of single grid from SQ150-PC panels. Each grid has 15 strings and each string has 32 panels.

converter steps up input dc voltage so that output voltage is always greater than the input voltage. Buck-boost is a type of converter that has an output voltage magnitude that is either greater than or less than the input voltage magnitude. Thus, this type of converter has a wide operating range but is somewhat costly to implement. This paper required the buck topology as output voltage is always less than input voltage. Under a wide range of solar irradiation variation, the maximum power point is always located inside the operating region of the buck converter [10], so this point can be tracked independently. Fig. 6 shows generic representation of buck converter which is represented by two semiconductor devices and three passive components and a voltage source. The voltage source represents the output voltage of the solar array.

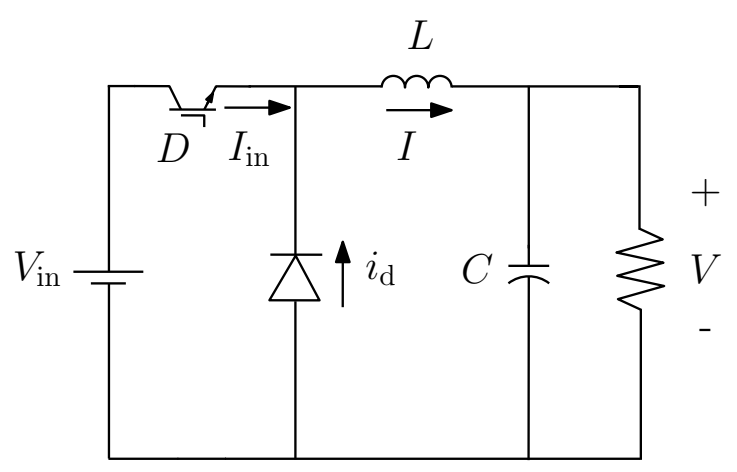

Fig. 6. Buck converter with two semiconductor switches.

Equations (4) and (5) describe the buck converter operation when operating in continuous conduction mode (CCM). The losses were neglected in this case and were based on the average model [11]:

$$
\begin{gathered}
V=D V_{\text {in }} \\
I=\frac{I_{\text {in }}}{D}
\end{gathered}
$$

where $D$ is the transistor duty ratio, $V$ is the output voltage, $V_{\text {in }}$ is the input voltage, $I_{\text {in }}$ is the input current, and $I$ is the output current. In a buck converter, there is no mismatch in current between the series connected modules because the current is boosted instead of the voltage. MPPT algorithms are used to track the peak power of PV arrays. The Perturb \& Observe $(\mathrm{P} \& \mathrm{O})$ method is the simplest form of the MPPT algorithm. There are several other methods available today for implementation of MPPT. The incremental conductance (IC) method, the artificial neural network method, and the fuzzy logic method are a few of these methods used in the perturbation of duty cycle of power converter to drive the operating current/voltage of the PV array. In this study, the buck converter with MPPT was chosen to extract maximum power from the arrays. The algorithm chosen was the $\mathrm{P} \& \mathrm{O}$ [12] type. The MPPT is subjected to generate the reference input current to maximize the input power delivered to the buck converter. The detail flow chart of the process is summarized in Fig. 7. It is the purpose of the MPPT system to sample the output of the PV panel and synthesize a proper duty cycle to obtain maximum power for any given irradiance. In this method, the controller adjusts the input current by a small amount from the array and measures power and if the power increases, further adjustments in that direction are tried until power no longer increases.

\section{STUDY OF CENTRALIZED ARCHITECTURE}

Centralized architecture is the most common type [12] for residential installations. Fig. 8 shows typical centralized architecture where only one dc/dc converter is used to boost voltage or current. For this paper, six PV arrays connected in series were used to study a simulated environment. As previously stated, real irradiance data were used to perform the analysis. Each array consisted of 465 panels. Array 1 was treated as the first grid, Array 2 as the second grid, and so on. The radiation pattern for each array or grid is shown in Fig. 4.

The output voltage of the buck converter (Fig. 6) was set to $800 \mathrm{~V}$. The average overall efficiency was $12.76 \%$ with an average dc power of $363 \mathrm{~kW}$. The average ideal power was $2.8475 \mathrm{MW}$ which can be computed as:

$$
P_{\text {ideal }}=G A_{\mathrm{C}},
$$

where $A_{\mathrm{C}}$ is the surface area of the PV array. The average maximum available power from the system was $377.57 \mathrm{~kW}$. The system was also subjected to conduction losses in the inductor, diode, and the transistor. The switching losses were 


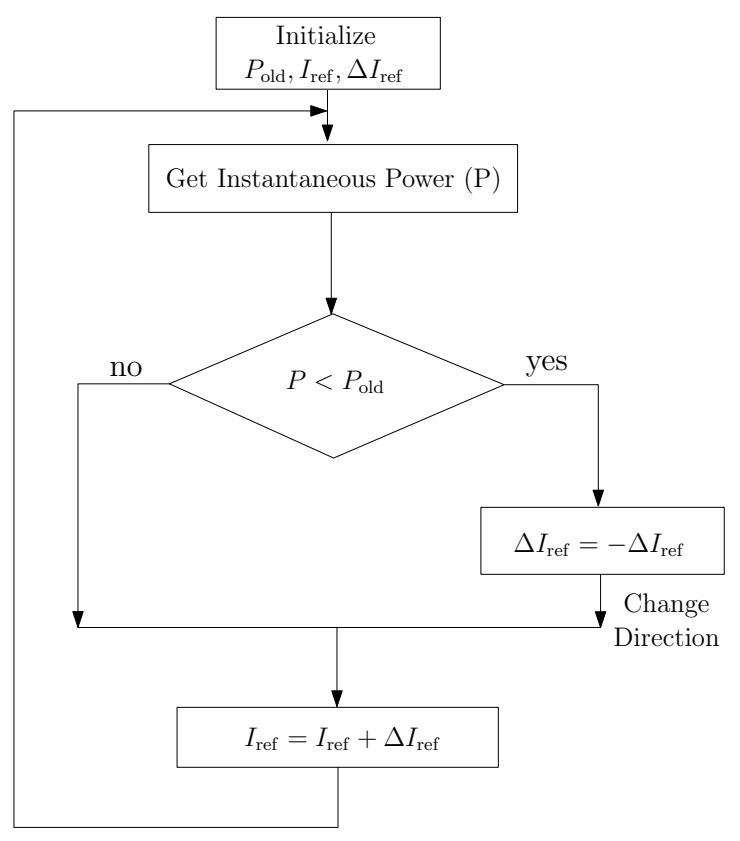

Fig. 7. $\mathrm{P} \& \mathrm{O}$ method used to perturb input current going to buck converter to maximize the output power of the solar array.

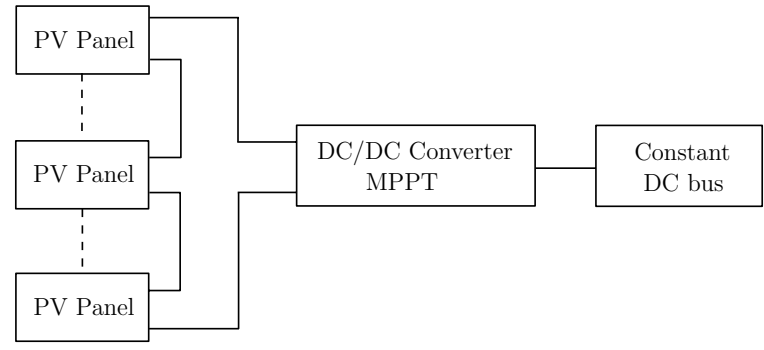

Fig. 8. Typical centralized scheme with only one converter.

also considered for simulation purposes. The detail analysis is presented in Section VII.

\section{STUDY OF MODULAR ARCHITECTURE AND COMPARISON}

This architecture has a "converter per panel" approach where each grid has a separate dc/dc converter for an individual MPP tracker. Fig. 9 shows a general layout of modular architecture where each array has separate $\mathrm{dc} / \mathrm{dc}$ converter with MPPT. These $\mathrm{dc} / \mathrm{dc}$ converters transfer the power generated by a PV grid to a constant dc bus. One of the major drawbacks of PV systems [13] is represented by the effect of module mismatching and of partial shading of the PV field in centralized architecture.

Modular scheme is a very promising technique that allows for an increase in overall efficiency and reliability of such systems. To prevent a mismatching effect, bypass diodes are usually placed in antiparallel fashion. The disadvantage of this is that it creates a power versus voltage curve multimodal as previously stated. Due to the series connection of the individual arrays, the output voltage of an individual array

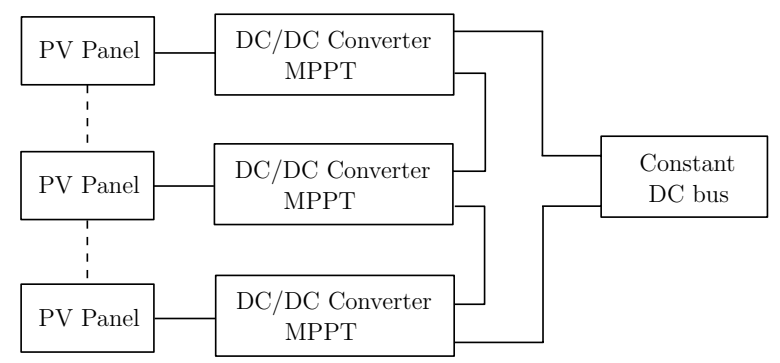

Fig. 9. Series-connected modular architecture with separate converter MPPT.

[13] can be found as follows:

$$
V_{\mathrm{i}}=\frac{P_{\mathrm{i}}}{P_{\mathrm{t}}} V_{\mathrm{t}}
$$

where $V_{\mathrm{i}}$ is the individual array voltage, $P_{\mathrm{i}}$ is the individual array power, $P_{\mathrm{t}}$ is the total system power, and $V_{\mathrm{t}}$ is the total system voltage. The advantages of the converter per panel [14] approach are better utilization on a per module basis, possible mixing of different sources, better protection of power sources, system redundancy, and better data gathering. Manufacturers have reported that eliminating electrolytic capacitors from their designs helps to increase the overall efficiency of the system. Thus, modular has a good potential for overall efficiency improvements when implemented correctly. The power ratio $K_{p}$ [15] determines the improvement over Centralized MPPT (CMPPT), which is defined as the ratio between the powers obtained using modular scheme and CMPPT:

$$
K_{\mathrm{P}}=\frac{P_{\text {modular }}}{P_{\text {cmppt }}} .
$$

The ratio must be greater than one for modular scheme to work. Predicting the actual energy of modular scheme requires knowing the time profile irradiation among the arrays and the power ratio. It was shown in several papers that modular architecture can result in up to $25 \%$ power savings compared to standard MPPT, which depends on the standard deviation in incident light. Each module with tracker is individually optimized to get maximum power from the grid [13]. The objective here is to extract maximum power while achieving the output dc Voltage of $800 \mathrm{~V}$ as in the previous case. All six grids with dc/dc converters are connected in series. Therefore, each converter is required to operate at a certain dc output voltage based on its maximum operating power. The output dc current is the same for the entire converter since converters are connected in series. The output voltage profile of each array is shown in Fig. 10. The output voltage of each grid or array is proportional to its irradiation level at particular time. Furthermore, it has been noticed that at any time the output voltage after the $\mathrm{dc} / \mathrm{dc}$ converter is always $800 \mathrm{~V}$ as expected.

Fig. 11 and Fig.12 show output power and overall efficiency plots for duration of 700 seconds. The maximum available overall efficiency was $13.25 \%$. Overall efficiency for modular scheme was $13.24 \%$ with dc output power equaling $377.01 \mathrm{~kW}$. 


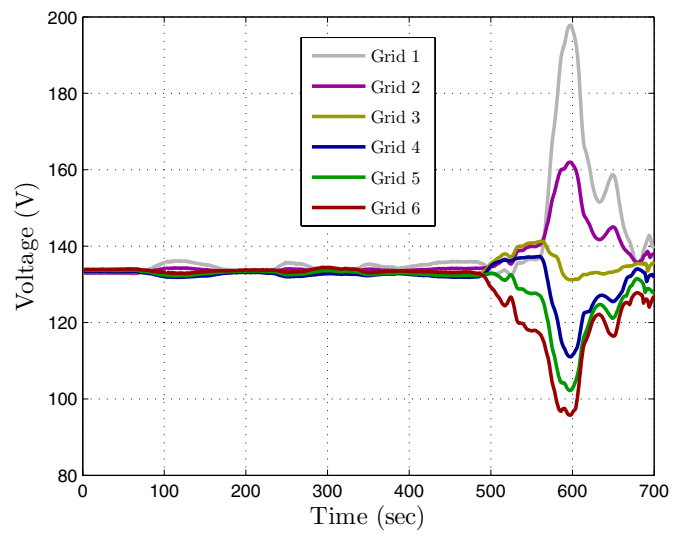

Fig. 10. Output voltage of the six grids of Station 1 over 700 seconds for the modular architecture.

The total output powers were almost identical with the maximum available power up to time equals 500 seconds, as the irradiance was almost equal for all grids as seen from Fig. 4. Centralized topology started losing track from the 500-second point until it hit 670 seconds. This suggests that the higher the variances in irradiance, the greater the power differences between CMPPT and modular architecture. Hence, the variance in irradiations was wide enough to affect system overall efficiency. The calculated mean power ratio $\left(K_{\mathrm{P}}\right)$ was found to be 1.0373 .

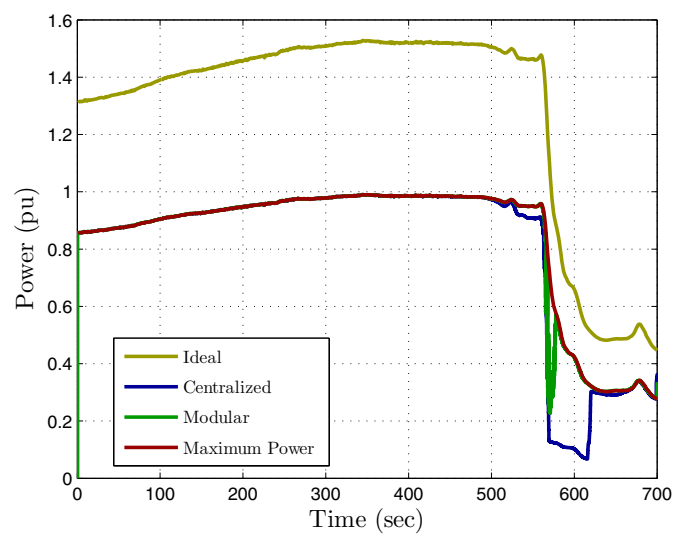

Fig. 11. Ideal, Maximum, CMPPT, Modular power plots over 700 seconds using per unit values (pu). The base power for ideal case is $2.2 \mathrm{MW}$ and for Maximum, CMPPT, and modular schemes it is $450 \mathrm{~kW}$. Actual power is a product of its pu value $\times$ base power.

\section{LOSS ANALYSIS}

For loss analysis in centralized topology, the $6.5 \mathrm{kV}, 750 \mathrm{~A}$ Insulated Gate Bipolar Transistor (IGBT) MBN750H65E2 and the $6.5 \mathrm{kV}, 600 \mathrm{~A}$ power diode were selected as semiconductor switches. The switching frequency for the $363.44 \mathrm{~kW}$ centralized and modular systems was chosen to be $5 \mathrm{kHz}$. The losses were comprised of two parts: conduction loss and switching loss. The conduction losses consisted of semiconductor losses

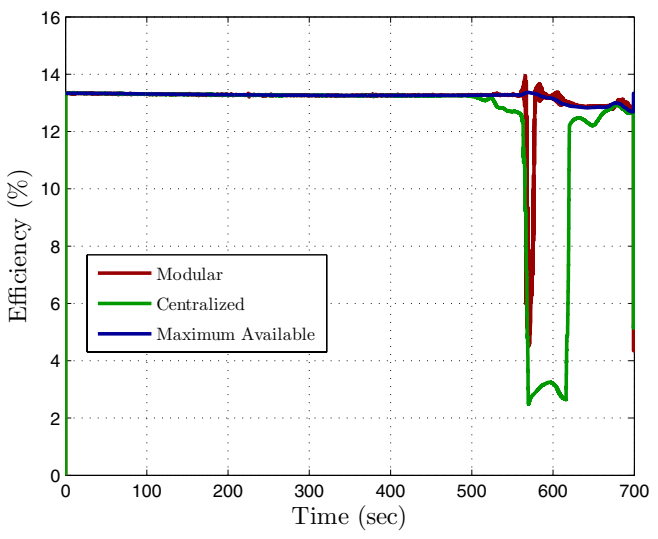

Fig. 12. Maximum, CMPPT and Modular efficiencies over 700 seconds.

and losses due to equivalent series resistance in the inductor. Of course, high switching frequency results in high switching losses.

The equations governing losses for IGBT [16] are summarized below in (9) and (10). It is assumed that buck converter operates in continuous conduction mode (CCM).

The parameters from corresponding datasheets were used for analysis purposes to match with actual scenarios. The same waveform was used to calculate root mean square (RMS) value of current.

$$
\begin{gathered}
P_{\mathrm{t}}=V_{\mathrm{ce}} I_{\mathrm{c}}+r_{\mathrm{c}} I_{\mathrm{crms}}^{2}+\left(V_{\mathrm{out}} \frac{I_{0}}{2}\right)\left(T_{\mathrm{on}}+T_{\mathrm{off}}\right) f_{\mathrm{sw}}, \\
I_{\mathrm{crms}}=I_{0} \sqrt{D\left[1+\frac{1}{3}\left(\frac{\text { ripple }}{I_{0}}\right)^{2}\right]} .
\end{gathered}
$$

In (9) and (10) $P_{\mathrm{t}}, V_{\mathrm{ce}}, I_{\mathrm{c}}, r_{\mathrm{c}}, I_{\mathrm{crms}}, V_{\mathrm{out}}, T_{\mathrm{on}}, T_{\mathrm{off}}, f_{\mathrm{sw}}$, $I_{0}, D$, and ripple stand for total power loss, IGBT saturation voltage, average current of IGBT, emitter on-state resistance, RMS value of collector current, output voltage, turn-on time, turn-off time, switching frequency, average IGBT current, duty cycle, and ripple factor respectively. The power loss due to inductor series resistance (ESR) is lumped to $0.8 \%$ of average power. The losses in a freewheeling diode can be summarized as

$$
P_{\mathrm{d}}=V_{\mathrm{d}} I_{\mathrm{d}}+r_{\mathrm{d}} I_{\mathrm{drms}}^{2}+Q_{\mathrm{rr}} f_{\mathrm{sw}} V_{\mathrm{in}}
$$

where $I_{\mathrm{d}}=(1-D) I_{0}$ and

$$
I_{\mathrm{drms}}=\sqrt{(1-D) \frac{1}{3}\left(I_{1}^{2}+I_{1} I_{2}+I_{2}^{2}\right)},
$$

with $I_{1}=I_{0}$ and $I_{2}=I_{0}-2$ (ripple). In the above equations, $P_{\mathrm{d}}, V_{\mathrm{d}}, I_{\mathrm{d}}, r_{\mathrm{d}}, I_{\mathrm{drms}}, Q_{\mathrm{rr}}$, and $V_{\mathrm{in}}$ stand for total power loss, diode forward voltage drop, average diode current, diode turn on resistance, RMS value of diode current, reverse recovery charge, and input voltage respectively. For modular topology, the $1.2 \mathrm{kV} 600 \mathrm{~A}$ IGBT CM600HA-24H and the $1.2 \mathrm{kV} 600 \mathrm{~A}$ fast recovery diode QRS1260T30 were chosen for study. The 
power loss due to inductor series resistance is again lumped to $0.8 \%$ of average output power as in previous case. Therefore, the total losses are the sum of IGBT, diode, and series inductor resistance losses for each module. The above equations were implemented in Matlab. The losses were calculated on the assumption that the converter stays on continuous conduction mode all the time. The switching loss is dominant at the chosen switching frequency of $5 \mathrm{kHz}$. Fig. 13 shows net power plots of centralized and modular architectures over 700 seconds. It can be seen that modular scheme generates more power than centralized scheme. The overall efficiency for centralized scheme was found to be $11.40 \%$ whereas for modular scheme it came out to be $12.63 \%$. The net gain in overall efficiency going from CMPPT to modular was $1.23 \%$. Losses due to capacitive elements were neglected in this analysis. To minimize capacitor losses, ceramic type capacitors of very little equivalent series resistance could be used.

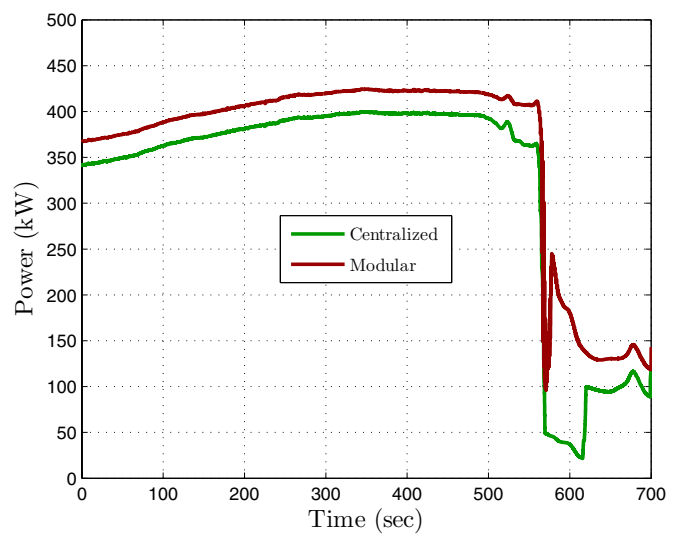

Fig. 13. Centralized and modular net power plots.

\section{CONCLUSION}

This paper has discussed comparisons between centralized and modular topologies using dc/dc converters. The modular architecture has resulted in more overall efficiency than its counterpart CMPPT under shading conditions such as clouds. It has been noticed that $\mathrm{P} \& \mathrm{O}$ fails to track the maximum power under a sharp change in irradiation patterns even in the case of modular topology. However, as shown in the trace of solar irradiance for 700 seconds, the sharp changes only occurs for a very short duration, once the solar irradiance settles to a new value, the MPPT will stabilize to new operating point. The standard temperature condition of $25^{\circ} \mathrm{C}$ has been considered for irradiation data. Note that the change in temperature will not likely to affect the function of MPPT because the power electronics operates much faster than the weather or temperature change. The actual temperature condition was not well known at the time of study. The buck type converter has been used in this study and another option is to use synchronous buck converter to increase overall efficiency. The $\mathrm{dc} / \mathrm{dc}$ converter is based on average model and we get satisfactory results from simulation. The losses have been modeled and quantify using Matlab/Simulink. The conduction and switching losses are based on datasheet parameters and are based on converter operating in continuous conduction mode all the time. The future study should include analysis using discontinuous conduction mode (DCM) which helps to further reduce the losses.

\section{ACKNOWLEDGMENT}

Mr. Bishal Dhakal would like to thank all of his colleagues at the University of Colorado Denver and Schneider Electric, who helped with their valuable suggestions and thoughts on various aspects of this paper.

\section{REFERENCES}

[1] W. G. D. W. Xiao, "Topology study of photovoltaic interface for maximum power point tracking," IEEE Transactions on Industrial Electronics, vol. 54, no. 3, pp. 1696-1704, June 2007.

[2] A photovoltaic systems using advanced mppt method implemented in matlab. [Online]. Available: http://www.eetimes.com/

[3] z. He, C. Liu, Y. Liu, Y. Zeng, and J. Pan, "Low cost mppt controller for off grid solar applications," in Proceedings of the International Conference on Electrical Machines and Systems (ICEMS), October 2010, pp. 447-451.

[4] U. Kamnarn, S. Yousawat, S. Sreeta, W. Muangjai, and T. Somsak, "Low cost mppt controller for off grid solar applications," in Proceedings of the $45^{\text {th }}$ International Universities Power Engineering Conference (UPEC), September 2010.

[5] A. Stjepanovic, F. Softic, Z. Bundalo, and S. Stjepanovic, "Low cost mppt controller for off grid solar applications," in Proceedings of the $33^{\text {rd }}$ International Convention, May 2010, pp. 105-109.

[6] A. Pavan, S. Castellan, S. Quaia, S. Roitti, and G. Sulligoi, "Power electronic conditioning systems for industrial photovoltaic fields: Centralized or string inverters?" in Proceedings of International Conference on Clean Electrical Power, May 2007, pp. 208-214.

[7] Y. Siwakoti, B. Chhetri, B. Adhikary, and D. Bista, "Microcontroller based intelligent dc/dc converter to track maximum power point for solar photovoltaic module," in Proceedings of IEEE Conference on Innovative Technologies for an Efficient and Reliable Electricity Supply, September 2010, pp. 94-101.

[8] G. Masters, Photovoltaic materials and electrical characteristics. John Wiley \& Sons, 2005.

[9] — Renewable and Efficient Electric Power Systems. New Jersey: Wiley-IEEE Press, 2004.

[10] R. Coelho, F. Concer, and D. Martins, "A study of the basic dc-dc converters applied in maximum power point tracking," in Proceedings of Brazilian Power Electronics Conference, October 2009, pp. 673-678.

[11] R. Erickson and D. Maksimovic, Fundamentals of Power Electronics. Boston: MA:Kluwer, 2000.

[12] K. Kim and P. Krein, "Photovoltaic converter module configurations for maximum power point operation," in Proceedings of Power and Energy Conference at Illinois, February 2010, pp. 77-82.

[13] N. Femia, G. Lisi, G. Petrone, G. Spagnuolo, and M. Vitelli, "Distributed maximum power point tracking of photovoltaic arrays: Novel approach and system analysis," IEEE Transactions on Industrial Electronics, vol. 55, no. 7, pp. 2610-2620, July 2008.

[14] G. Walker and P. Sernia, "Cascaded dc-dc converter connection of photovoltaic modules," IEEE Transactions on Power Electronics, vol. 19, no. 4, pp. 1130-1139, July 2004.

[15] S. Poshtkouhi, J. Varley, R. Popuri, and O. Trescases, "Analysis of distributed peak power tracking in photovoltaic systems," in Proceedings of International Power Electronics Conference, June 2010, pp. 942-947.

[16] Infineon. [Online]. Available: http://www.btipnow.com/ 